Alison M. Campbell MBChB FRCA, Nicola Thompson MBChB FRCA

\title{
Anaesthesia for Caesarean section in a patient with myotonic dystrophy receiving warfarin therapy
}

A 31-yr-old parturient with myotonic dystrophy and asthma presented for elective Caesarean section. The patient was receiving warfarin having had two previous episodes of thromboembolism. Anticoagulation was subsequently provided by heparin in the weeks prior to delivery. The combination of the patient's medical conditions and the continuing need for anticoagulation presented a considerable anaesthetic problem in planning anaesthesia and analgesia for both elective and emergency delivery. Heparin was discontinued on the day prior to surgery and restarted immediately after surgery. During surgery flowtron anti-embolitic boots were used. Warfarin therapy was recommenced on the seventh postoperative day. Anciesthesia for Caesarean section was provided using a combined spinal epidural technique using a separate needle, separate interspace method. Postoperative pain was relieved by using a continuous epidural infusion, transcutaneous nerve stimulation and diclofenac. No new neurological problems arose despite the use of epidural analgesia in the presence of heparin anticoagulation. This method of providing anaesthesia and postoperative analgesia without the use of opioids in an anticoagulated, asthmatic, myotonic parturient has not been described elsewhere.

\section{Key words}

ANAESTHESIA: obstetric;

ANAESTHETIC TECHNIQUES, REGIONAL: epidural, spinal; BLOOD, ANTICOAGULANTS: heparin, warfarin; COMPLICATIONS: myotonias.

From the Department of Anaesthesia, Aberdeen Royal Hospitals NHS Trust, Foresterhill, Aberdeen, Scotland. AB9 2ZB.

Address correspondence to: Dr. A.M. Campbell, Department of Anaesthesia, Aberdeen Royal Hospitals NHS Trust, Foresterhill, Aberdeen, Scotland. AB9 2ZB. Accepted for publication 20th January, 1995.
Une parturiente de 31 ans souffrant de dystrophie myotonique et d'asthme est programmée pour une césarienne en chirurgie réglée. Cette patiente reçait déjà de la warfarine à cause de deux épisodes thromboemboliques antérieurs. Pendant les semaines qui précèdent l'extraction par césarienne, l'anticoagulation était assurée par de lhéparine. La condition de la patiente et la nécessité de continuer l'anticoagulation créent un très sérieux problème de planification pour l'anesthésie et l'analgésie tant pour les extractions réglées que les extractions urgentes. Lhéparine est interrompue le jour précédant la chirurgie et reprise immédiatement après la chirurgie. Pendant la chirurgie, des bottes anti-emboliques (mécanisme de compression intermittente) sont utilisées. La warfarine est reprise sept jours après l'intervention. L'anesthésie pour la césarienne consiste en une technique rachidienne-épidurale qui utilise des aiguilles et des espaces intervertébraux indépendants. La douleur postopératoire est traitée par une perfusion épidurale continue, la stimulation nerveuse transcutanée et l'administration de diclofénac. Aucun nouveau problème neurologique n'apparâ̂t malgré l'utilisation de l'analgésie épidurale et l'anticoagulation à l'héparine. Cette méthode de procurer l'anesthésie et l'analgésie postopératoires sans utiliser de morphinique chez une patiente anticoagulée, asthmatique et myotonique n'a pas été décrite ailleurs.

Myotonic dystrophy is an autosomal dominant degenerative condition. It is the most common and most severe of the myotonic syndromes with a prevalence of 3-5 in 100,000 . $^{\text {I }}$ Myotonic dystrophy is a multisystem disorder involving not only skeletal but also smooth and cardiac muscle and thus presents serious anaesthetic problems. ${ }^{2}$ Myotonia is characterized by difficulty in initiating muscle movement with delayed muscle relaxation following contraction. Myotonia may be precipitated by cold, shivering and diathermy, and succinylcholine. ${ }^{3}$

The clinical syndrome usually presents in early childhood with myotonia, progressive weakness and wasting of the muscles of the face, sternocleidomastoids, distal extremities and respiration. ${ }^{4}$ Patients display abnormal 
sensitivity to premedicant drugs, anaesthetic induction agents, opioids and non-depolarizing neuromuscular blocking drugs. ${ }^{1}$ Respiratory failure is a frequent cause of postoperative morbidity. ${ }^{5}$ Cardiac involvement is common with progressive deterioration in the conducting system resulting in heart block and sudden death. ${ }^{6}$ Heart failure and cardiomyopathy have been described in pregnancy. ${ }^{7}$

Pregnancy in myotonic dystrophy although uncommon, because of ovarian failure, is frequently complicated and may require anaesthetic assistance. ${ }^{8,9}$ The use of regional anaesthesia has been described in the parturient but does not prevent myotonic spasms and may present particular problems in the pregnant myotonic who is at increased risk of post-partum haemorrhage. ${ }^{10}$ Deterioration of the disease may occur in pregnancy, with exacerbation of the muscle weakness, myotonia and muscle wasting, and of the extramuscular manifestations. "

Complications of pregnancy include polyhydramnios, premature onset of labour, breech presentation, and ineffective uterine contractions during labour. ${ }^{12}$ Following delivery there is an increased incidence of uterine inertia, retained placenta and post-partum haemorrhage. ${ }^{13}$ Upper gastrointestinal tract incoordination increases the risk of aspiration in the pregnant myotonic. ${ }^{14}$ The baby has a $50 \%$ chance of being affected and the neonatal death rate is high. ${ }^{\text {Is }}$

Spinal and epidural anaesthesia have each been used for Caesarean section, ${ }^{16-18}$ but if the patient has been treated with warfarin or heparin, many anaesthetists would avoid regional anaesthesia. ${ }^{19}$

We describe the anaesthetic management of a parturient receiving long-term anticoagulation who required delivery by Caesarean section. The patient had a fear of general anaesthesia and the possibility of postoperative ventilation in the intensive therapy unit (ITU). She also wished to share the pleasure of the birth of the baby, which had a high risk of developing myotonia, with her husband.

A combined spinal epidural technique was successfully used. This has not been described elsewhere in this particular situation.

\section{Case report}

A 31-yr-old gravida two, para one, woman with myotonic dystrophy was referred by the obstetrician at $34 \mathrm{wk}$ gestation so that anaesthetic management could be planned for elective delivery, and consideration given to any emergency situation which might arise. Caesarean section was scheduled to take place at 37 wk gestation. She was receiving warfarin therapy following a pulmonary thromboembolism occurring eight weeks after her first delivery, three years previously. The patient had also had a femoral deep vein thrombosis three years before her first pregnancy.

The diagnosis of myotonic dystrophy had been made by a neurologist one year after her first pregnancy. The condition was confirmed by electromyography (EMG) which showed the typical "dive-bomber" response, ${ }^{4}$ and by muscle biopsy. Analysis of her DNA myotonin kinase gene showed a large expansion of the unstable trinucleotide repeat, compatible with her clinical status. The patient had received two general anaesthetics before the diagnosis of myotonic dystrophy, both of which were unremarkable. During her first labour the patient received diamorphine $10 \mathrm{mg} \mathrm{im}$, followed by epidural analgesia. The epidural block was subsequently extended to provide anaesthesia for an emergency Caesarean section necessitated by fetal distress. No ill effects were noted.

Following the diagnosis of myotonia the patient underwent general anaesthesia for dental extractions on a day-care basis, on two separate occasions 18 mo apart. The anaesthetic was administered by the same anaesthetist, who noted a considerable deterioration in the patient's muscle power and an increased sensitivity to all the anaesthetic agents administered. The drugs used included oral temazepam premedication, $10 \mathrm{mg}$, followed by a propofol induction, $80 \mathrm{mg}$ on the first and $20 \mathrm{mg}$ on the second occasion. Maintenance of anaesthesia was with halothane in nitrous oxide and oxygen with spontaneous respiration being maintained throughout. Isoflurane was substituted during the second anaesthetic and on each occasion tracheal intubation was accomplished without the use of a muscle relaxant drug. The patient made an uneventful recovery each time.

Shortly after the diagnosis of myotonia, she was confined to a wheelchair and required assistance with bathing and dressing.

Other medical history include diarrhoea, early lens opacification and asthma. The asthma was well controlled with salbutamol and beclomethasone inhalers.

Her second pregnancy was complicated by nine antenatal admissions mostly related to deteriorations in her myotonia. Complaints consisted of chest pain, dyspnoea, several chest infections, abdominal pain, reduced fetal movement and a sustained reduction in power in one arm and one leg.

At the first meeting, the patient was sitting in a wheelchair. At 34 wk gestation she weighed $68.5 \mathrm{~kg}$, height $155 \mathrm{~cm}$, her pre-pregnancy weight was $54 \mathrm{~kg}$. She displayed the typical myotonic facies with temporal balding, bilateral ptosis and thinning of her neck muscles. Speech was dysarthric. Examination of the airway revealed full frontal dentition with prominent upper incisors, a high arched palate and receding lower mandible. Mallampati class was graded as III, although intubation difficulties 
had not been remarked upon in previous anaesthetic records. Examination of the respiratory system revealed poor chest expansion but no other abnormality. Cardiovascular examination was unremarkable. Neurological examination revealed a myotonic grip in both hands, wasting of the small muscles of the hand and forearm, reduced power in all four limbs and absent deep tendon reflexes. Sensation was intact.

Results of clinical investigations were as follows. International Normalized Ratio (INR) was maintained at 2.5 , on a dose of warfarin $2-4 \mathrm{mg}$ daily. Haemoglobin, white cell count and platelets were within normal limits. Biochemistry was normal. Arterial blood gases were: $\mathrm{pH}$ $7.42, \mathrm{PCO}_{2} 4.8 \mathrm{kPa}, \mathrm{PO}_{2} 11.4 \mathrm{kPa}$. A chest $x$-ray was clear. Electrocardiogram (ECG) revealed no conduction abnormalities. Echocardiography was normal.

Pulmonary function tests showed an obstructive ventilatory defect with reductions in functional residual capacity, vital capacity and total lung capacity.

Pulmonary function tests were as follows: peak expiratory flow rate (PEFR) $340 \mathrm{~L} \cdot \mathrm{min}^{-1}$, forced expiratory volume in one minute $\left(\mathrm{FEV}_{1}\right) 1.3 \mathrm{~L}$, forced vital capacity (FVC) $1.9, \mathrm{FEV}_{\mathrm{l}} / \mathrm{VC} 68 \%$, functional residual capacity (FRC) $1.2 \mathrm{~L}$, residual volume (RV) $0.8 \mathrm{~L}$, vital capacity (VC) $2.2 \mathrm{~L}$, total lung capacity (TLC) $3.0, \mathrm{RV} / \mathrm{TLC} 27 \%$.

Heparin, 20,000 u daily was substituted for warfarin at 35 wk gestation. The heparin was administered by continous subcutaneous infusion and a daily activated partial thromboplastin time (APTT) was monitored and heparin dosage adjusted to achieve an APTT of twice the control value. Heparin therapy was discontinued the day before surgery. Haematology results on the morning of surgery were as follows: prothrombin time (PT) 13.3 $\mathrm{sec}$, thrombin clotting time (TCT) $16.9 \mathrm{sec}$, APTT 39.2 sec, haemoglobin $135 \mathrm{~g} \cdot \mathrm{L}^{-1}$, platelet count $354 \times$ $10^{9} \cdot \mathrm{L}^{-1}$.

Premedication consisted of ranitidine $150 \mathrm{mg}$ po the evening before and again on the morning of surgery. After transfer to the operating theatre, sodium citrate 0.3 M $30 \mathrm{ml}$ po was given. An $i v$ cannula was inserted into a peripheral vein, infusion of saline $0.9 \%$ was commenced and a preload of $500 \mathrm{ml}$ infused. Non-invasive monitoring was instituted, consisting of ECG, blood pressure measurement and oxygen saturation. Metoclopramide $10 \mathrm{mg}$ iv was given. With the patient in the sitting position, an epidural catheter was inserted at the $\mathrm{L}_{1}-\mathrm{L}_{2}$ interspace, using loss of resistance to air to identify the epidural space. A test dose of $3 \mathrm{ml}$ plain bupivacaine $0.5 \%$ was given with no evidence of intrathecal injection. A 25 gauge Whitacre spinal needle was used to administer an intrathecal dose of $2.25 \mathrm{ml}$ hyperbaric bupivacaine $0.5 \%$ at the $\mathrm{L}_{3}-\mathrm{L}_{4}$ interspace. The patient was lowered to a lying position with a $15^{\circ}$ left lateral tilt on the operating table. Skin prick testing revealed a sensory block to $T_{4}$ bilaterally, and surgery was allowed to commence. Oxygen, $4 \mathrm{~L} \cdot \min ^{-1}$ was administered via a face mask up to the time of delivery. Ephedrine $6 \mathrm{mg} \dot{i}$ was administered to treat an isolated decrease in blood pressure to $80 / 50 \mathrm{mmHg}$. Otherwise the blood pressure was maintained throughout with a systolic pressure of $>100$ $\mathrm{mmHg}$. Heart rate was steady between 80 and 100 beats per minute, in sinus rhythm, and oxygen saturation remained $>95 \%$. Following delivery, oxytocin $10 \mathrm{u} i v$ was given, producing sustained uterine contraction. No further syntocinon was required. The patient was delivered of an apparently healthy boy weighing $2,540 \mathrm{~g}$.

Surgery proceeded uneventfully with blood loss of 300 $\mathrm{ml}$. At no time did the level of sensory block extend above the $T_{4}$ dermatome bilaterally. Heparin $10,000 \mathrm{u}$ sc twice daily, was recommenced immediately after surgery. Flowtron anti-embolism calf boots had been in use during the procedure. The patient was transferred to a high-dependency recovery area. Postoperative pain relief was provided by epidural infusion of bupivacaine $0.1 \%$ at a rate of $10 \mathrm{ml} \cdot \mathrm{hr}^{-1}$.

This provided excellent pain relief overnight. However, the following morning the epidural catheter fell out and as the patient was by now anticoagulated it was not reinserted. Pain relief was subsequently provided by a transcutaneous nerve stimulator and, as the patient was not allergic to aspirin, diclofenac suppositories $100 \mathrm{mg} \mathrm{pr}$ were administered on a regular basis.

On the first postoperative day the patient showed signs of developing a chest infection with a low grade pyrexia and increased sputum production. This was treated with prompt and regular physiotherapy and antibiotics. Warfarin 2-4 mg po was substituted for heparin on the seventh postoperative day, and the heparin discontinued on the tenth postoperative day. The patient remained in hospital for 15 days after delivery before being discharged home.

A set of pulmonary function tests performed six months post partum showed a moderately large restrictive ventilatory defect. Results of pulmonary function testing were as follows: $\mathrm{FEV}_{1}$ 1.3L, FVC 1.6L, $\mathrm{FEV}_{1} / \mathrm{VC}^{2} 1 \%$. Other lung variables were not measured.

\section{Discussion}

The medical problems present in this patient posed a particular dilemma for the anaesthetist. Neither general nor regional anaesthesia prevent myotonia, as it is a primary myopathy. The use of topical and local anaesthetic infiltration has been described in preventing myotonia during surgery. ${ }^{20,21}$ Local anaesthetic infiltration was dismissed in our patient due to operator inexperience and its unsuitability in an emergency situation as it takes time 
to perform and would be contra-indicated if the patient were still anticoagulated. Topical application of bupivacaine $0.5 \%,{ }^{20}$ to the uterus was discussed with the surgeon, but did not prove necessary as uterine myotonia was not encountered.

Sufferers are particularly sensitive to all central nervous system (CNS) depressants and the incidence of postoperative respiratory problems is high. ${ }^{5}$ This patient had displayed marked sensitivity to propofol during a previous anaesthetic, although recovery was unremarkable. A higher incidence of difficult intubation has been found in these patients due to maxillofacial deformities ${ }^{22}$ and, indeed, the facial characteristics of this patient suggested this. In addition this patient suffered from asthma which probably contributed to her reduced respiratory reserve. Antenatal respiratory function tests showed an obstructive pattern compatible with asthma; however, a further set of tests carried out postnatally demonstrated a restrictive pattern which was more in keeping with her myotonia.

Taking into account the above points and the patient's own desire to remain awake, regional anaesthesia for $\mathrm{Cae}-$ sarean section seemed a safer option.

A combined spinal epidural technique was chosen in order to obtain optimum conditions for surgery and patient comfort. Epidural anaesthesia alone provides a slower onset block with a reduced frequency and severity of maternal hypotension. The final sensory level can be titrated by the addition of local anaesthetic. In addition, anaesthesia can be maintained indefinitely, an advantage in repeat Caesarean section. The epidural catheter can be left in place to provide postoperative pain relief. However, compared with spinal anaesthesia, epidural anaesthesia carries a greater likelihood of failure due to technical problems. ${ }^{23}$ Epidural anaesthesia also requires larger doses of local anaesthetic with a consequent increase in neonatal exposure and an increase in maternal shivering. ${ }^{24}$ Spinal anaesthesia provides a faster onset, more reliable block than epidural anaesthesia, using a much smaller dose of local anaesthetic. However, disadvantages of spinal anaesthesia include a greater risk of hypotension with attendant nausea and vomiting, the possibility of post-dural puncture headache and a limited duration of action. ${ }^{25}$

By combining spinal with epidural anaesthesia it was hoped to obtain the best from each technique and minimise the side effects. The epidural catheter was inserted first and a test dose administered in order to identify accidental intrathecal placement. The spinal anaesthetic was then administered with careful attention to dose and patient posture to minimise the effects of a rapid onset blockade on maternal blood pressure. The epidural catheter would have allowed the addition of small doses of local anaesthetic to adjust the final sensory level, without increasing the risk of shivering. Shivering has been reported to occur in up to $61 \%$ of patients who undergo Caesarean section with epidural anaesthesia. ${ }^{24}$ Shivering is not only distressing for the patient, ${ }^{26}$ but it interferes with monitoring and may induce myotonia. ${ }^{\prime}$ Epidural fentanyl has been demonstrated to reduce the incidence of shivering during Caesarean section. ${ }^{27}$ However, epidural opioids carry the risk of maternal respiratory depression, ${ }^{28}$ and we felt it important to avoid opioids by any route, including epidural, in a patient with increased CNS sensitivity to opioids. ${ }^{29}$ The addition of intrathecal opioids to local anaesthetics can improve the quality and duration of intraoperative analgesia. ${ }^{23}$ This route of administration of opioid was rejected as it can cause respiratory depression in normal parturients. ${ }^{30}$

Post-partum haemorrhage due to uterine hypotonia may be a problem in the myotonic parturient, ${ }^{13}$ and is less easily managed after regional blockade, but is reported to respond well to oxytocin infusions. ${ }^{31}$ In this case sustained uterine contraction was achieved with a single dose of oxytocin $10 \mathrm{u}$, and an oxytocin infusion was not necessary. There remained the problem of anticoagulant therapy and the need to formulate a plan should the need for emergency Caesarean section arise, for example due to acute cord prolapse or antepartum haemorrhage. In that event, heparin anticoagulation would have been stopped and clotting factors administered in the form of fresh frozen plasma. ${ }^{32}$ The use of incremental protamine sulphate to reverse heparin anticoagulation in this situation has been described. ${ }^{33}$ To facilitate tracheal intubation atracurium with the priming principle ${ }^{34}$ has been used successfully. ${ }^{9}$ Succinylcholine is contraindicated because it can provoke myotonic spasm making intubation and ventilation impossible. ' Intubation following propofol was dismissed as unsuitable for a rapid-sequence induction where the risk of regurgitation is even higher in the myotonic parturient. ${ }^{14}$ Vecuronium has also been used to facilitate tracheal intubation in the myotonic parturient. ${ }^{8}$ Postoperative morbidity and mortality are usually due to respiratory problems and the patient would have been transferred to the ITU immediately after surgery, for monitoring and provision of analgesia. Myotonic patients are extremely sensitive to systemic opioids, although the use of patient-controlled analgesia has been described. ${ }^{8}$ Fortunately no emergency arose and anticoagulation therapy was stopped for $24 \mathrm{hr}$ allowing regional anaesthesia and surgery to be performed without the risk of haemorrhage. A combined spinal epidural technique was chosen in that it combined good anaesthesia for surgery with the flexibility of extending a low block. A separate interspace method was 
chosen so that an epidural test dose could be administered prior to performing the spinal injection. A warm theatre, warming of all intravenous fluids and careful handling of tissues by the surgeon avoided any myotonic spasms.

By leaving the epidural catheter in place, postoperative pain relief was provided in an asthmatic patient sensitive to opiates and possibly non-steroidal anti-inflammatory drugs (NSAIDS).

Heparin anticoagulation following epidural anaesthesia carries a small but definite risk of epidural haematoma formation. ${ }^{35,36}$ Other studies, ${ }^{37,38}$ have demonstrated only minor and no permanent neurological sequelae when the therapeutic heparin was commenced after regional blockade. The decision to recommence heparin in the presence of an epidural catheter was a considered risk in this patient. The patient was post partum following a surgical delivery and wheelchair-bound with a history of thromboembolic disease. It was felt that the risk of further thromboemboli was a more immediate, life-threatening problem than the risk of epidural haematoma formation where the insertion of the catheter had been atraumatic. In addition the epidural catheter provided valuable postoperative pain relief in a patient in whom it was important to avoid opioids.

The loss of the epidural catheter on the first postoperative day necessitated an alternative method of analgesia. Transcutaneous nerve stimulation (TNS) was useful not only in reducing wound pain but pain from myotonic spasms in her legs. The use of diclofenac in an asthmatic was a considered risk taken as she was not allergic to aspirin. ${ }^{39}$

In summary, successful management of the parturient with myotonic dystrophy can be achieved by good liaison with obstetric staff and early referral to formulate a management plan. A thorough preoperative assessment of the patient is required with particular reference to functional disability, respiratory function and cardiovascular abnormalities. In addition to haemoglobin, urea and electrolytes, ECG and chest $x$-ray, ante natal investigation should include echocardiography, pulmonary function tests and arterial blood gas analysis. Perioperative anticoagulation adds an additional risk to the parturient with an already increased chance of peripartum haemorrhage, therefore additional blood should be cross matched and the blood bank warned of the potential need for fresh frozen plasma. Provision for invasive cardiovascular monitoring should be made in the event of massive haemorrhage. Finally, delivery should take place in a unit which is equipped to resuscitate and manage a potentially affected baby, and be able to provide appropriate postoperative high dependency care of the mother.
References

1 Russell SH, Hirsch NP. Anaesthesia and myotonia. $\mathrm{Br} \mathrm{J}$ Anaesth 1994; 72: 210-6.

2 Aldridge LM. Anaesthetic problems in myotonic dystrophy. Br J Anaesth 1985; 57: 1119-30.

3 Mitchell MM, Ali HH, Savarese JJ. Myotonia and neuromuscular blocking agents. Anesthesiology 1978; 49: 44-8.

4 Jozefowicz RF, Griggs RC. Myotonic dystrophy. Neurol Clin 1988; 6: 455-72.

5 Mudge BJ, Taylor PB, Vanderspek AFL. Perioperative hazands in myotonic dystrophy. Anaesthesia 1980; 35 : 492-5.

6 Hawley RJ, Milner MR, Gottdiener JS, Cohen A. Myotonic heart disease: a clinical follow-up. Neurology 1991; 41: 259-62.

7 Fall LH, Young WW, Power JA, Falkner CS II, Hettleman $B D$, Robb JF. Severe congestive heart failure and cardiomyopathy as a complication of myotonic dystrophy in pregnancy. Obstet Gynecol 1990; 76: 481-5.

8 Blumgart $C H$, Hughes $D G$, Redfern $N$. Obstetric anaesthesia in dystophia myotonica. Anaesthesia 1990; 45 : 26-9.

9 Walpole AR, Ross AW. Acute cord prolapse in an obstetric patient with myotonia dystrophica. Anaesth Intensive Care 1992; 20: 526-8.

10 Hook $R$, Anderson EF, Noto $P$. Anesthetic management of a parturient with myotonia atrophica. Anesthesiology 1975; 43: 689-92.

11 Hopkins $A$, Wray $S$. The effect of pregnancy on dystrophia myotonia. Neurology 1967; 17: 166-8.

12 Webb D, Muir I, Faulkner J, Johnson G. Myotonia dystrophica: obstetric complications. Am J Obstet Gynecol 1978; 132: 265-70.

13 Shore RN, MacLachlan TB. Pregnancy with myotonic dystrophy. Course, complications and management. Obstet Gynecol 1971; 38: 448-54.

14 Horowitz M, Maddox A, Maddern GJ, Wishart J, Collins $P J$, Shearman DJC. Gastric and esophageal emptying in dystrophia myotonica. Gastroenterology 1987; 92: 570-7.

15 Nazir MA, Dillon WP, McPherson EW. Myotonic dystrophy in pregnancy. J Reprod Med 1984; 29: 168-72.

16 Camann WR, Johnson MD. Anesthetic management of a parturient with myotonia dystrophica: a case report. Reg Anesth 1990; 15: 41-3.

17 Stevens JD, Wauchob TD. Dystrophia myotonica - emergency Caesarean section with spinal anaesthesia. Eur $\mathbf{J}$ Anaesthesiol 1991; 8: 305-8.

18 Harris MNE. Extradural analgesia and dystrophia myotonia (Letter). Anaesthesia 1984; 39: 1032-3.

19 Wildsmith $J A W$, McLure JH. Anticoagulant drugs and central nerve blockade (Editorial). Anaesthesia 1991; 46: 613-4. 
20 Cope DK, Miller JN. Local and spinal anesthesia for cesarean section in a patient with myotonic dystrophy. Anesth Analg 1986; 65: 687-90.

21 Wheeler AS, James FM III. Local anesthesia for laparoscopy in a case of myotonia dystrophica (Letter). Anesthesiology 1979; 30: 169.

22 Müller $H$, Punt-van Manen JA. Maxillo-facial deformities in patients with dystrophia myotonica and the anaesthetic implications. Journal of Maxillofacial Surgery 1982; 10: 224-8.

23 Lussos SA, Datta S. Anesthesia for cesarean delivery. Part II: Epidural anesthesia. Intrathecal and epidural opioids. Venous air embolism. International Journal of Obstetric Anesthesia 1992; 1: 208-21.

24 Morgan BM, Aulakh JM, Barker JP, Reginald PW, Goroszeniuk $T$, Trojanowski $A$. Anaesthetic morbidity following Caesarean section under epidural or general anaesthesia. Lancet 1984; 1: 328-30.

25 Lussos SA, Datta $S$. Anesthesia for cesarean delivery. Part I: General considerations and spinal anesthesia. Internation Journal of Obstetric Anesthesia 1992; 1: 79-91.

26 Crossley AWA. Peri-operative shivering (Editorial). Anaesthesia 1992; 47: 193-5.

27 Liu WHD, Luxton MC. The effect of prophylactic fentanyl on shivering in elective Caesarean section under epidural analgesia. Anaesthesia 1991; 46: 344-8.

28 Brockway MS, Noble DW, Sharwood-Smith GH, McClure $J H$. Profound respiratory depression after extradural fentanyl. Br J Anaesth 1990; 64: 243-5.

29 Ogawa K, Iranami H, Yoshiyama T, Maeda H, Hatano $Y$. Severe respiratory depression after epidural morphine in a patient with myotonic dystrophy. Can J Anaesth 1993; 40: 968-70.

30 Hays RL, Palmer CM. Respiratory depression after intrathecal sufentanil during labor. Anesthesiology 1994; 81 : 511-2.

31 Paterson RA, Tousignant $M$, Skene DS. Caesarean section for twins in a patient with myotonic dystrophy. Can Anaesth Soc J 1985; 32: 418-2I.

32 Maternal and Neonatal Haemostasis Working Party of the Haemostasis and Thrombosis Task. Guidelines on the prevention, investigation and management of thrombosis associated with pregnancy. J Clin Pathol 1993; 46: 489-96.

33 Saka DM, Marx GF. Management of a parturient with cardiac valve prosthesis. Anesth Analg 1976; 55: 214-6.

34 Foldes $F$. Rapid tracheal intubation with nondepolarizing neuromuscular blocking drugs: the priming principle (Letter). Br J Anaesth 1984; 56: 663.

35 Helperin $S W$, Cohen $D D$. Hematoma following epidural anesthesia: report of a case. Anesthesiology 1971; 35: 641-4.
36 DeAngelis $J$. Hazards of subdural and epidural anaesthesia during anticoagulant therapy: a case report and review. Anesth Analg 1972; 51: 676-9.

37 Rao TLK, El-Etr AA. Anticoagulation following placement of epidural and subarachnoid catheters: an evaluation of neurologic sequelae. Anesthesiology 1981; 55: 618-20.

38 Odoom JA, Sih IL. Epidural analgesia and anticoagulant therapy. Experience with one thousand cases of continuous epidurals. Anaesthesia 1983; 38: 254-9.

39 Power I. Aspirin-induced asthma (Editorial). $\mathrm{Br} \mathrm{J}$ Anaesth 1993; 71: 619-21. 